\title{
Residual radioactivity from the treatment of water for urban domestic applications
}

\author{
R. Kleinschmidt \\ Queensland Health Scientific Services, Queensland Department of \\ Health, Brisbane. Australia
}

\begin{abstract}
An assessment of radiologically enhanced residual materials generated during treatment of domestic water supplies in southeast Queensland, Australia was conducted. Radioactivity concentrations of ${ }^{3} \mathrm{H},{ }^{210} \mathrm{Po},{ }^{222} \mathrm{Rn},{ }^{226 / 228} \mathrm{Ra}$, uranium and thorium in water sourced from both surface water catchments and ground water resources were examined both pre- and post-treatment under typical water treatment plant operations. Surface water treatment processes included sedimentation, coagulation, flocculation and filtration, while the groundwater was treated using cation exchange resins. Waste products generated during treatment included sediments, filtration media, used ion exchange resin, backwash and wastewaters. Elevated residual concentrations of radionuclides were identified in these waste products. The waste product activity concentrations were used to model the radiological impact of the materials when either utilised for beneficial purposes, or upon disposal. The results indicate that, under current water resource exploitation programs, reuse or disposal of the treatment wastes do not pose a significant radiological risk, however, regulatory disposal limits may be exceeded for disposable carbon filters from household point-of-use treatment systems. The impact of population growth and changes in water supply sources are also considered.
\end{abstract}

Keywords: water treatment, radioactivity, TENORM, waste.

\section{Introduction}

As the population of southeast Queensland, Australia, continues to increase, the need for adequate water resources will continue to expand. Alternative supplies will be required to meet the demands for water as traditional sources become 
stressed, and technology based intervention and treatment will become more common as poorer quality alternative water supplies are exploited.

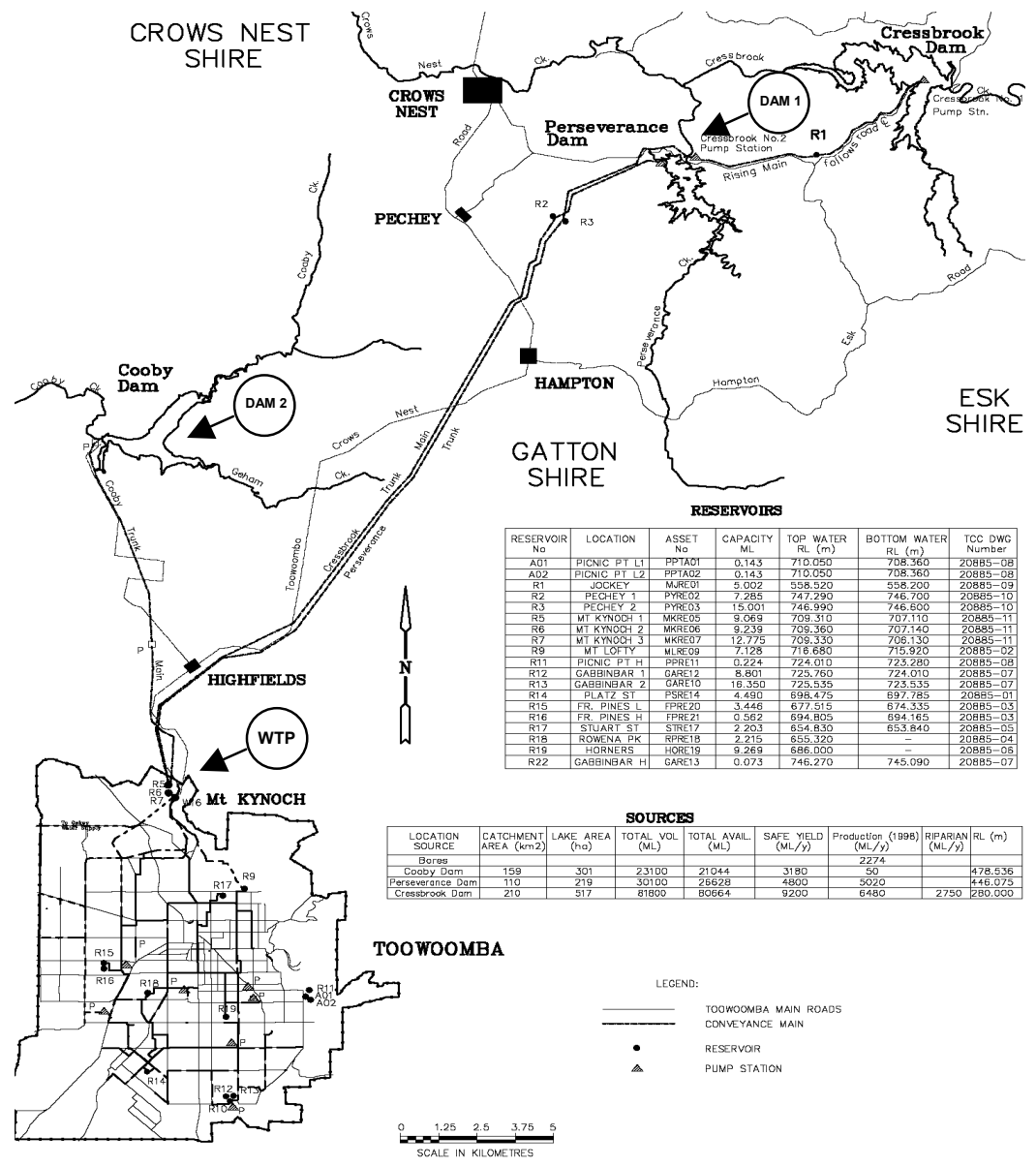

Figure 1: Toowoomba surface water supply and water treatment plant locations.

While radiological water quality is addressed at considerable length by local guideline documents (drinking water - NHMRC/ARMCANZ [1]; Irrigation, recreational and stock watering - ANZECC/ARMCANZ [2]) and globally (WHO [3], USEPA [4], EU [5] and Kocher [6]), the impact of contaminants, either naturally occurring or artificially introduced, removed from water upon treatment, and discharge of waste waters that may have become radiologically contaminated, is limited. The subject of generation of Technologically Enhanced Naturally Occurring Radioactive Materials (TENORM) during water resource exploitation is a current topic both locally (Cooper [7], RHSAC [8]) and 
internationally (IAEA [9]). Cooper [7] concedes that local information is extremely limited and recommends an investment in defining the magnitude of TENORM generation.

This study was based on the small city of Toowoomba, with a population of approximately 117000 people. Toowoomba is situated about $130 \mathrm{~km}$ west of Brisbane, the capital of Queensland, and is situated on the eastern rim of the Australian Great Dividing Range. Toowoomba was chosen for the study as it is typical of small cities in the region, undergoing continued growth $(1.4 \%$ per annum, QDLGPSR [10]) and drawing its water supply from a combination of both surface and groundwater, specifically three surface water catchment and storage dams, and thirteen groundwater bores (Figure 1). Table 1 provides data relevant to the study. Current water consumption is approximately $14500 \mathrm{ML}$ per annum, with $89 \%$ provided from the storage dams and the remaining $11 \%$ from bores (QHSS [11]).

The surface water treatment plant (WTP) consists of a series of stages including flocculation (aluminium sulphate and polydadmac), settling, filtration and post filtration chemical dosing. Supernatant from the settling tanks is recycled to the head of the plant for reprocessing. The filtration system consists of a bed of anthracite filter coal over graded sand and fine gravel. Backwash from the filter beds is recycled to the head of the plant for reprocessing. Dried sludge generated from the plant is stockpiled on site and removed for beneficial land-use applications, including use as a soil conditioner.

The groundwater bores are located throughout the city and tap into a number of disjointed aquifers. Only 2 bores were in use at the time of this study. In both cases the groundwater is passed through a cation exchange resin prior to injection into the city water distribution system. Wastes generated by the system include old exchange resin and regeneration backwash. Disposal of the expired resin is achieved by controlled landfill while the regeneration backwash fluids are discharged to the sewer.

There are no local nuclear industries other than limited unsealed medical and sealed industrial sources and it is assumed that naturally occurring radionuclides are the predominant species.

Table 1: Water statistics and treatment data for this assessment.

\begin{tabular}{lcc}
\hline Description & & \multicolumn{1}{c}{ REF } \\
\hline Total water supplied - 2004 & $14587 \mathrm{ML} /$ year & QDNRM [12] \\
Total connections & 44878 & QDNRM [12] \\
Total litres/connection/day & $936 \mathrm{~L} /$ day & QDNRM [12] \\
Total litres/drinking-cooking-washing up/day & $100 \mathrm{~L} /$ day & Lawson [13] \\
Number of Dams & 3 & QDNRM [12] \\
Number Bores (in use) & $13(2)$ & QDNRM [12] \\
Solid waste - WTP & 290 tonne/year & QHSS [11] \\
Solid waste - bores & 12.8 tonne/year & QHSS [11] \\
Liquid waste - bores (1300 L/regen x 300/year) & 390000 L/year & QHSS [11] \\
Number of POUs in use (15\% of connections) & 6700 & Lawson [13] \\
\hline
\end{tabular}




\section{Experimental/materials and methods}

\subsection{Sampling}

Water samples were collected in $10 \mathrm{~L}$ acid washed polyethylene bottles for ${ }^{3} \mathrm{H}$, ${ }^{210} \mathrm{Po},{ }^{226} \mathrm{Ra}$, uranium and thorium radionuclide assay methods. Samples were acid preserved in the laboratory after filtration and sub-sampling.

Samples for dissolved ${ }^{222} \mathrm{Rn}$ analysis were collected in either $20 \mathrm{~mL}$ glass scintillation vials (groundwater) or 1 litre acid washed glass Erlenmeyer flasks (surface water). Environmental samples were collected by gently submerging the $1 \mathrm{~L}$ flask beneath the water surface to the desired sampling depth. The cap was removed and the flask filled to capacity, the cap being replaced while still submerged to eliminate any headspace. Sampling of water from distribution systems was conducted using a plastic hose immersed in the flask and adjusting the flow rate until a constant, turbulence-free flow of water was established. This flow of water was maintained until the sample bottle overflowed and at least 3 volumes of water had washed through the system. The hose was gently removed and the vial capped ensuring elimination of headspace. Samples were then chilled on ice and returned to the laboratory for analysis as soon as possible.

Sediment, sludge, ion exchange resin and filter bed samples were collected in either $1 \mathrm{~L}$ detergent washed glass bottles or clean plastic bags.

\section{$2.2 \quad$ Methods}

\subsubsection{Water}

2.2.1.1 Tritium $\left({ }^{3} \mathbf{H}\right)$ Tritium in water measurement was conducted using a method described in ISO 9698 [14]). Samples were counted on a Packard 3170 TR/SL liquid scintillation analyser (LSA). A minimum detection level of 1.5 Bq. $\mathrm{L}^{-1}$ was obtained for the method using a 400 min count time.

2.2.1.2 Radon $\left({ }^{222} \mathrm{Rn}\right)$ Two methods were used for ${ }^{222} \mathrm{Rn}$ analysis depending on the required minimum detection level. Direct counting was conducted on $15 \mathrm{~mL}$ aliquots of water after addition of $5 \mathrm{~mL}$ of a mineral oil based scintillation cocktail.

The ${ }^{222} \mathrm{Rn}$ samples collected in $1 \mathrm{~L}$ Erlenmeyer flasks were opened and $20 \mathrm{~mL}$ of water removed and discarded. The void was replaced with $15 \mathrm{~mL}$ of mineral oil scintillator and the flask recapped. The flask was then vigorously shaken for 15 minutes to allow for the preferential transfer of dissolved radon into the scintillation cocktail. After separation of the aqueous phase (24 hours), the scintillator was extracted for counting. All samples were sealed and allowed to sit for a minimum of 3 hours to allow in-growth of decay progeny.

Counting of samples from either method was conducted using the LSA. Respective minimum detection levels of $80 \mathrm{mBq} \cdot \mathrm{L}^{-1}$ and $12 \mathrm{mBq} \cdot \mathrm{L}^{-1}$ were obtained using these methods for a count time of 250 minutes.

2.2.1.3 Radium ( $\left.{ }^{226} \mathrm{Ra}\right) \quad$ The ${ }^{222} \mathrm{Rn}$ emanation method was used for ${ }^{226} \mathrm{Ra}$ determinations. Samples were prepared by pre-concentrating $1000 \mathrm{~mL}$ of water 
sample to $15 \mathrm{~mL}$ by evaporation. The concentrated samples were transferred to Teflon coated poly vials and $5 \mathrm{~mL}$ of mineral oil scintillator added to trap the radon gas. The vials were capped and stored for a minimum of 15 days to allow ingrowth of ${ }^{222} \mathrm{Ra}$. Analysis was conducted as for the ${ }^{222} \mathrm{Rn}$ method. A minimum detection level of $1.4 \mathrm{mBq} . \mathrm{L}^{-1}$ was obtained using this method for a 180 minute counting period.

2.2.1.4 Polonium $\left({ }^{210} \mathrm{Po}\right){ }^{210} \mathrm{Po}$ was determined using a method published by EML [15]. Water samples of $1000 \mathrm{~mL}$ were pre-concentrated by evaporation to a volume of $200 \mathrm{~mL}$ before ${ }^{210}$ Po deposition on $20 \mathrm{~mm}$ diameter nickel foil discs. The foils were transferred to a $20 \mathrm{~mL}$ polyethylene scintillation vial, cocktail added and then counted with the LSA. Extraction and alpha counting efficiency were observed to be greater than $60 \%$ for the method with a minimum detection level of $8 \mathrm{mBq} . \mathrm{L}^{-1}$ for a counting time of 180 minutes.

2.2.1.5 Uranium Uranium analysis was conducted using direct measurement of ${ }^{238} \mathrm{U}$ by ICPMS (Agilent 7500 ICPMS Chem Station) using in-house methods (QHSS [16]).

2.2.1.6 Thorium Thorium was determined as ${ }^{232}$ Th by ICPMS simultaneously with ${ }^{238} \mathrm{U}$ analysis.

\subsubsection{Waste solids}

Radioactivity concentrations in solid wastes were determined using high resolution gamma-ray spectrometry (EG\&G Gamma-X, $\sim 40 \%$ rel. eff. + EG\&G Dspec Plus spectrometer). The spectrometer was calibrated using IAEA RGU-1 reference material in a standard geometry. Samples were dried to constant mass and sealed in $100 \mathrm{~mL}$ polyethylene jars for a minimum of 20 days (to allow ${ }^{238} \mathrm{U}$ series decay progeny to reach secular equilibrium) before counting. Typical counting times were 100000 seconds.

\subsection{Models}

Two models were used to determine the impact of residual radioactivity associated with water treatment. The models used were RESRAD (ANL [17]) and CARBDOSE (USEPA [18]). RESRAD was used to model the potential radiological dose associated with the beneficial land application of solid wastes derived from the water treatment plant (WTP), and with landfill of spent ion exchange resins from the groundwater treatment plants (GWTP).

The CARBDOSE model was used to estimate the residual activity present on granulated activated carbon point-of-use (POU) filters.

\section{Results and discussion}

Table 2 provides a summary of results for water sampled at the WTP and GWTPs, while Table 3 provides solid waste radioactivity concentrations. 
Table 2: $\quad$ Radioactivity concentrations in water samples.

\begin{tabular}{|c|c|c|c|c|c|c|}
\hline \multirow[t]{2}{*}{ Sample } & \multicolumn{2}{|c|}{ Bq. $\mathrm{L}^{-1}$} & \multicolumn{4}{|c|}{ 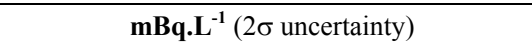 } \\
\hline & ${ }^{3} \mathbf{H}$ & ${ }^{222} \mathbf{R n}$ & ${ }^{226} \mathrm{Ra}$ & ${ }^{210} \mathrm{Po}$ & ${ }^{238} \mathbf{U}$ & ${ }^{232} \mathrm{Th}$ \\
\hline Dam 1 (Persev) & $1.1(1.3)$ & $0.02(0.01)$ & $1.6(1.1)$ & $11.5(5.7)$ & $0.78(0.06)$ & $<0.04$ \\
\hline Dam 2 (Cooby) & $1.5(1.3)$ & $0.15(0.07)$ & $10(2)$ & $6.5(5.2)$ & $2.93(0.23)$ & $<0.04$ \\
\hline WTP - Raw & $0.1(1.3)$ & $0.08(0.02)$ & $2.0(1.2)$ & $6.7(5.3)$ & $1.23(0.10)$ & $<0.04$ \\
\hline WTP - Supernatant & - & - & $1.1(1.0)$ & $4.7(5.0)$ & $1.87(0.15)$ & $<0.04$ \\
\hline WTP - Treated & $0.2(1.3)$ & $0.03(0.02)$ & $0.5(1.0)$ & $9.3(4.9)$ & $1.77(0.14)$ & $<0.04$ \\
\hline Bore 1 - Raw & $0.6(1.3)$ & $13.0(0.7)$ & $1.5(1.1)$ & $253(13)$ & $0.15(0.01)$ & $<0.04$ \\
\hline Bore 1 - Treated & $0.3(1.3)$ & $10.6(0.6)$ & $1.0(1.0)$ & $24(7)$ & $0.15(0.01)$ & $<0.04$ \\
\hline Bore 2 - Raw & $0.2(1.3)$ & $17.2(0.9)$ & $0.1(0.9)$ & $52(9)$ & $0.77(0.06)$ & $<0.04$ \\
\hline Bore 2 - Treated & $1.0(1.3)$ & $14.6(0.8)$ & $2.7(1.3)$ & $2.1(4.9)$ & $0.78(0.06)$ & $<0.04$ \\
\hline Bore 2 - Regen & $1.3(1.3)$ & $4.2(0.5)$ & $21(10)$ & $3.8(4.9)$ & $3.18(0.25)$ & $<0.04$ \\
\hline Consumer Pt 1 & $-0.7(1.2)$ & $0.03(0.02)$ & $3.0(1.3)$ & $9.0(5.5)$ & $1.07(0.08)$ & $<0.04$ \\
\hline Consumer Pt 2 & - & $8.9(1.0)$ & - & - & $1.25(0.10)$ & $<0.04$ \\
\hline Consumer Pt 3 & - & $0.21(0.08)$ & - & - & $0.70(0.06)$ & $<0.04$ \\
\hline
\end{tabular}

Table 3: $\quad$ Radioactivity concentrations in solid waste material.

\begin{tabular}{lcccccc}
\hline Sample & \multicolumn{5}{c}{ Bq.kg ${ }^{-1}-$ dry weight } & \multicolumn{3}{c}{$(2 \sigma$ uncertainty) } \\
& ${ }^{238} \mathbf{U}$ & ${ }^{226} \mathbf{R a}$ & ${ }^{\mathbf{2 1 0}} \mathbf{P b}$ & ${ }^{228} \mathbf{R a}$ & ${ }^{\mathbf{4 0}} \mathbf{K}$ & ${ }^{7} \mathbf{B e}$ \\
\hline WTP sludge $<30 \mathrm{~d}$ & $140(50)$ & $37(6)$ & $89(32)$ & $46(5)$ & $110(30)$ & $170(35)$ \\
WTP sludge $>$ 60 d & $134(33)$ & $39(3)$ & $77(15)$ & $50(5)$ & $85(14)$ & $20(6)$ \\
WTP f/coal - New & $63(15)$ & $13(3)$ & $12(10)$ & $16(4)$ & $60(20)$ & $<11$ \\
WTP f/coal - Used & $31(12)$ & $16(2)$ & $15(8)$ & $12(2)$ & $<18$ & $<7$ \\
Bore 1 resin - New & $<11$ & $<2$ & $<12$ & $<4$ & $<21$ & $<8$ \\
Bore 1 resin - Used & $<16$ & $6(4)$ & $113(16)$ & $<8$ & $57(27)$ & $<14$ \\
\hline
\end{tabular}

\subsection{Surface water treatment plant}

It was observed that the ${ }^{238} \mathrm{U}$ concentration in treated water was higher than the raw water entering the treatment plant. Subsequent investigation established that a proportion of the excess ${ }^{238} U$ present within the system is associated with leaching of uranium from the anthracite filter coal utilised in the plant and recycling of supernatant from the sludge settling tanks. Activity-balance calculations for ${ }^{210} \mathrm{Po},{ }^{226} \mathrm{Ra}$ and ${ }^{238} \mathrm{U}$ accounted for ${ }^{210} \mathrm{Po}$ to within $5 \%$ and ${ }^{238} \mathrm{U}$ to within $20 \%$, however, it was observed that there is retention of ${ }^{226} \mathrm{Ra}$ in the system with $85 \%$ being held back in the WTP.

\subsubsection{Sludge}

The RESRAD model was used to calculate the additional radiation dose to a critical group (small crop farmer) associated with the beneficial use of the sludge 
produced from the WTP. Radionuclide concentrations used in the model are based on the residual activities derived from the $>60$ day old sludge (Table 3). Results are calculated assuming that the total annual inventory of $290000 \mathrm{~kg}$ of sludge is applied in a $50 \mathrm{~mm}$ layer to the surface of a $4000 \mathrm{~m}^{2}$ field. Table 4 shows the calculated results. A maximum dose of $78 \mu \mathrm{Sv} \cdot \mathrm{y}^{-1}$ was calculated for a time period of less than 1 year, decreasing to $\sim 30 \mu \mathrm{Sv}^{-1} \mathrm{y}^{-1}$ after 10 years and 0 $\mu \mathrm{Sv} . \mathrm{y}^{-1}$ at 100 years.

Table 4: $\quad$ RESRAD dose results for beneficial reuse of sludge.

\begin{tabular}{lcc}
\hline Contribution from: & Effective Dose $\left(\mu \mathbf{S v} \cdot \mathbf{y}^{-\mathbf{1}}\right)$ & \% of total dose \\
\hline Ground & 40.3 & 52 \\
Inhalation (excluding radon) & 0.7 & 1 \\
Radon & 20.7 & 26 \\
Ingestion (soil) & 1.7 & 2 \\
Remainder (plant/meat/milk) & 14.5 & 19 \\
TOTAL & $\mathbf{7 7 . 9}$ & $\mathbf{1 0 0}$ \\
\hline
\end{tabular}

\subsection{Groundwater treatment plants}

\subsubsection{Ion exchange resin}

The cation exchange resin used in the two operational bores is not changed regularly, and may be used for up to 10 years. The waste resin $(\sim 6500 \mathrm{~kg} / \mathrm{bore})$ is buried in a controlled landfill with a minimum cover of $1000 \mathrm{~mm}$ of clean fill. The RESRAD model was used to calculate radiation dose to a landfill operator critical group. It is assumed that the controlled landfill site has been designed to minimise contamination of local surface and groundwater. Table 5 shows the calculated results. A maximum dose of $4.4 \mu \mathrm{Sv}^{-1} \mathrm{y}^{-1}$ was calculated for a time period of less than 1 year, decreasing to $2.8 \mu \mathrm{Sv}^{-1} \mathrm{y}^{-1}$ at 100 years. The total contribution arises from ${ }^{222} \mathrm{Rn}$ emanation.

Table 5: $\quad$ RESRAD dose results for controlled landfill of spent resin.

\begin{tabular}{lcc}
\hline Contribution from: & Effective Dose $\left(\mu \mathbf{S v}_{\mathbf{y}} \mathbf{y}^{-\mathbf{1}}\right)$ & $\boldsymbol{\%}$ of total dose \\
\hline Radon & 4.4 & 100 \\
Remainder (ground/inhalation/plant etc.) & 0 & 0 \\
TOTAL & 4.4 & $\mathbf{1 0 0}$ \\
\hline
\end{tabular}

\subsubsection{Resin regeneration}

Regeneration is conducted on the bore 2 GWTP on a daily basis determined by water flow \& volume. The regeneration waste $(390000 \mathrm{~L} / \mathrm{year})$ is directly discharged to the domestic wastewater system. For the radionuclides examined, 
the most restrictive sewer disposal criterion is for ${ }^{210} \mathrm{Po}$ at $2.04 \mathrm{kBq} \cdot \mathrm{m}^{-3}$ (OQPC [19]). Results in Table 2 indicate that in all cases the activity concentrations for ${ }^{210} \mathrm{Po}$ are significantly less than the specified release criteria.

\subsection{Point-of-use granulated activated carbon filters}

Granulated activated carbon filters (GAC) in POU units are known to effectively remove ${ }^{222} \mathrm{Rn}$ and are installed in up to $15 \%$ of households (Lawson [13]). The units are fitted as under-sink units and treat water used for drinking, cooking and washing up, typically treating $100 \mathrm{~L}$ of water per day. Toowoomba groundwater contains ${ }^{222} \mathrm{Rn}$ concentrations up to 15 Bq. $\mathrm{L}^{-1}$ at the pump stations and 9 Bq.L ${ }^{-1}$ at consumer points throughout the city (Table 2). CARBDOSE was used to model ${ }^{222} \mathrm{Rn}$ activities present on GAC filters for radon activity concentrations of a maximum of $10 \mathrm{~Bq} . \mathrm{L}^{-1}$ and a mean of $3 \mathrm{~Bq} . \mathrm{L}^{-1}$ at $95 \%$ removal efficiency and $100 \mathrm{~L}$ per day (Table 1).

Table 6: CARBDOSE results for activity retained on GAC filters.

\begin{tabular}{ccc}
\hline $\begin{array}{c}\text { Supply }{ }^{222} \mathbf{R n} \\
\text { Concentration } \\
\left(\text { Bq. } \mathbf{L}^{-1}\right)\end{array}$ & $\begin{array}{c}\text { 222Rn activity on filter } \\
\text { @ 100 days } \\
(\mathbf{k B q})\end{array}$ & $\begin{array}{c}\text { Progeny activity concentration on } \\
\text { filter @ 100 years } \\
\left(\mathbf{k B q} \cdot \mathbf{k g}^{-1}\right)\end{array}$ \\
\hline 3 & 15.7 & 1.8 \\
10 & 52.4 & 49.9 \\
\hline
\end{tabular}

Landfill disposal criteria for ${ }^{210} \mathrm{~Pb}+$ decay progeny is $5 \mathrm{kBq} \cdot \mathrm{kg}^{-1}$ (OQPC [19]). The data in Table 6 indicates that the disposal criterion is exceeded for situations where expired GAC filter cartridges are placed in municipal landfills after use in filtering water with ${ }^{222} \mathrm{Rn}$ concentrations of $10 \mathrm{~Bq} \cdot \mathrm{L}^{-1}$.

\section{Conclusions}

An assessment of radiologically enhanced residual materials generated when treating water for a small city was conducted. The water supply was drawn from both surface and groundwater resources. All radioactive constituent concentrations monitored fell within current Australian drinking water guideline values (NHMRC/ARMCANZ [1] \& ANZECC/ARMCANZ [2]).

Activity balance calculations were performed for radionuclides within the WTP and inventories of ${ }^{210} \mathrm{Po}$ and ${ }^{238} \mathrm{U}$ could be accounted for within measurement uncertainty constraints. An as yet unidentified ${ }^{226} \mathrm{Ra}$ retention mechanism is holding back greater than $80 \%$ of the radionuclide. It was identified that filter media and recycled process waters may act as temporary sinks for radionuclides within the surface water treatment plant. Further work is required to fully characterise the ${ }^{226} \mathrm{Ra}$ activity balance of the system.

Sludge generated during surface water treatment contained enhanced concentrations of ${ }^{238} \mathrm{U},{ }^{226} \mathrm{Ra}$ and ${ }^{210} \mathrm{~Pb}$. Modelling the additional dose to a small 
crops farmer (as the critical group) using the sludge as a soil conditioner provides a maximum dose of $78 \mu \mathrm{Sv}$ per year.

Additional dose associated with the disposal of exhausted ion exchange resin from the groundwater treatment plants to a controlled landfill was calculated for landfill plant operators. Results indicate that an additional dose of less than $5 \mu \mathrm{Sv}$ per year can be attributed to the practice.

Regeneration wastes derived from the groundwater treatment plants are discharged to the sewer. Current radionuclide concentrations in the regeneration waste do not exceed regulatory limits for discharge to the sewer (OQPC [19]).

Granulated activated carbon filter cartridges used in household point-of-use water treatment filters may contain ${ }^{222} \mathrm{Rn}$ decay progeny at levels that exceed regulatory disposal criteria for landfill disposal. Individual GAC filter compliance with regulatory waste disposal criteria will be determined by the location of the user within the city supply area, the status of groundwater supplementation and mixing of surface and groundwater within the distribution system.

Additional work is underway to further characterise ${ }^{222} \mathrm{Rn}$ concentration in the water distribution system by sampling a larger number of consumer outlets. This data will be used to further assess regulatory compliance issues.

This study forms a preliminary stage of a broader study assessing the impact of waterborne radioactivity in urban and rural environments. This data will be used in validating a computer model developed to assess the radiological impact of water supply, treatment, distribution, wastewater collection and treatment processes, and ultimate discharge to the environment as either waste or a beneficial material, particularly with a view to future increases in resource exploitation and population growth.

\section{Acknowledgements}

The author is indebted to the management and staff of Toowoomba Water, Toowoomba City Council for providing access to sampling locations, infrastructure and information relevant to their water treatment plants and distribution systems. Acknowledgement is also extended to Mr Allan Burton, of Queensland Health Scientific Services for his assistance in sample preparation.

\section{References}

[1] NHMRC/ARMCANZ. Australian Drinking water Guidelines 1996 Update 2001. National Water Quality Management Strategy Paper No. 6, National Health and Medical Research Council \& Agricultural and Resource Management Council of Australia and New Zealand, Australian Government Publishing Service, Canberra. 2001

[2] ANZECC/ARMCANZ. Australian and New Zealand Guidelines for Fresh and Marine Water Quality. National Water Quality Management Strategy Paper No. 4. Australian and New Zealand Environmental and Conservation Council \& Agricultural and Resource Management Council of Australia and New Zealand. Australian Government Publishing Service. Canberra. 2000 
[3] WHO. Guidelines for drinking-water quality, $3^{\text {rd }}$ Edition. World Health Organisation. Geneva. 2004

[4] USEPA. National Primary Drinking Water Regulations; Radionuclides; Final Rule. Environmental Protection Agency 40 CFR Parts 9, 141 and 142: Washington, USA. 2000

[5] EU. Drinking Water Directive. Council Directive 98/83/EC on the quality of water intended for human consumption. European Commission. 1998

[6] Kocher, DC. Drinking water standards for radionuclides: the dilemma and a possible resolution. Health Physics 80: 486-490. 2001

[7] Cooper, MB. Naturally Occurring Radioactive Materials (NORM) in Australian Industries - Review of Current Inventories and Future Generation. Report prepared for the Radiation Health \& Safety Advisory Council, ERS-006 EnviroRad Services Pty Ltd. Australia. 2003

[8] RHSAC. Naturally Occurring Radioactive Material (NORM) in Australia: Issues for Discussion. Radiation Health \& Safety Advisory Council Report to the CEO, ARPANSA. Australia. 2004

[9] IAEA. Extent of Environmental Contamination by Naturally Occurring Radioactive Material (NORM) and Technological Options for Mitigation. Technical Report Series No. 419. Vienna: International Atomic Energy Agency. 2003

[10] QDLGPSR. Population and Housing fact Sheet - Toowoomba City. Queensland Government, Department of Local Government, Planning, Sport and Recreation, Brisbane. Australia. 2004

[11] QHSS. Water Treatment Survey - Toowoomba City Council. Conducted by Queensland Health Scientific Services, unpublished data. Brisbane. Australia. 2004

[12] QDNRM. Annual water statistics report 2003 - 2004, Queensland Department of Natural Resources and Mines. Brisbane. Australia. 2004

[13] Lawson, B. Personal communication, 20 April 2005, Aqua Fresh Water Purifying Systems, Brisbane. Australia

[14] ISO9698. Water quality - Determination of tritium activity concentration - Liquid scintillation counting method. International Standard 9698. International Organisation for Standardisation, Geneva. Switzerland. 1989.

[15] EML. Environmental Measurement Laboratory Procedures Manual, HASL-300, $28^{\text {th }}$ Edition. US Department of Energy. New York. 1997

[16] QHSS. Trace Elements in Clinical Samples, Waters and Digests by ICPMS, Method. QIS Document No. 18229R2. Brisbane. Australia. 2000

[17] ANL. RESRAD Version 6.22 Computer Model. ANL, Argonne. USA

[18] USEPA. CARBDOSE Version 5.0 Computer model. USEPA, Boston. USA

[19] OQPC. Radiation Safety Regulation 1999, Reprint No. 2H, April 2005. Office of the Queensland Parliamentary Counsel, Brisbane. Australia. 